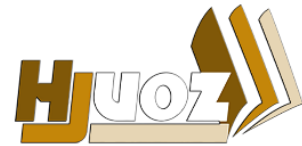

hjuoz.uoz.edu.krd p-ISSN: $2410-7557$
كوّاقارا زانستيّن مروّقايهتى يا زانكوّيا زاخوّ

مجلة العلوم الانسانية لجامعة زاخو

Humanities Journal of University of Zakho (HJUOZ)

Vol. 5, No. 1, pp. 81-88, March-2017

\title{
الجذور التاريخية للأرمن في زاخو
}

عماد عبدالقادر محمد سعيد

قسم التاريخ، فاكلتي العلوم الانسانية، جامعة رابه رين، إقليم كردستان، العراق. (Imadabid73@yahoo.com)

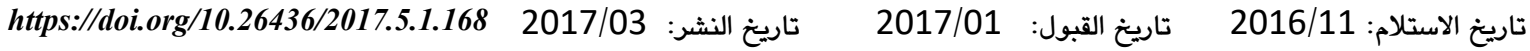

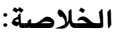

تعتبر المدن الكوردية موئلاً للعديد من الشعوب والاقوام والطوائف الدينية المتباينة،حيث عاشت تلك الشعوب والاطياف في كنف الكورد، ولعل من بين تلك المدن التي ضمت في طياتها عناصر دينية وقومية عدة هي مدينة (زاخو)، التي إثتهرت بخليطها وينيتها الدينية والعرقية المعقدة، ويمعنى

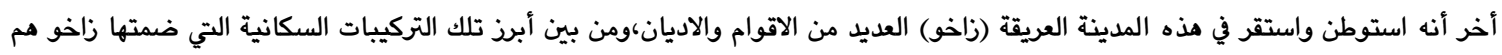

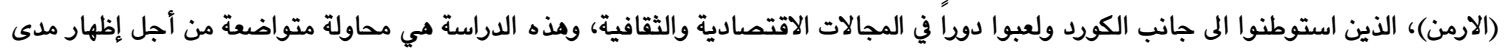

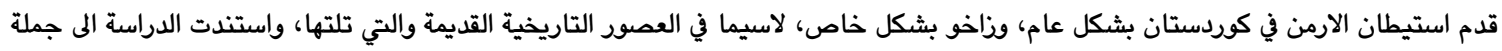

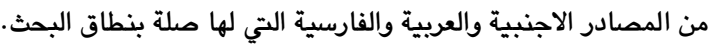
تم تقسيم الدراسة الى مبحثين، تطرق المبحث الاول الى الاراء التي قيلت بشأن أصل الارمن والتسمية مستندين الى أبرز المصادرالقيمة التي وردت

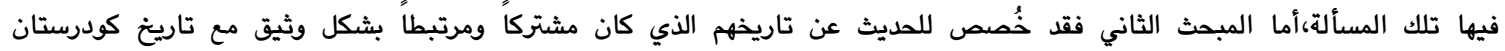

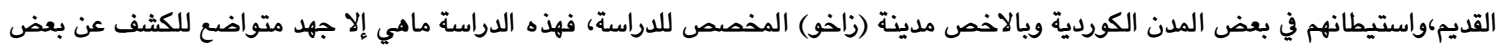

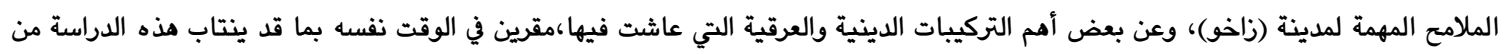
النواقص، وعليه نأمل أن يكون هذا الجهد تأدية لمهام واقعة على عاتقنا ويساهم في دراسته في ملء الفراغ لمثل تلك الدراسات المتعلقة بمدينة

زاخو.

\section{الكلمات الدالة: تاريخ، الارمن، زاخو.}

يبين الدود التاريخي للارمن وجذورهم الموغلة في القدم في كوردستان على العموم، وزاخو على الاخص.

\section{2. الارمن التسمية والاصل:}

ذهبت بعض الدراسات الاثارية والانثروبولوجية الى أنه من الصعب إمكان تقسيم الشعوب بصورة قطعية حسب إختلافات ظاهرية في أجسامهم أو تشابه في لغاتهم وتفريقهم الى أجناس بمجرد ذلك،لاسيما الشعوب القاطنة في الشرق القديم، وذلك يعود لكثرة الامتزاج بين بعضها البعض، كما أن دراسة الاجناس البشرية من التصاوير التي خلفها الشعوب والحضارات القديمة لذو صعوية بالغة، ولايمكن الاعتماد عليها

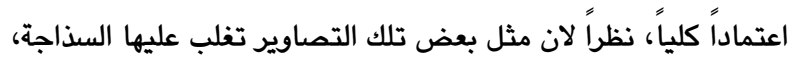

$$
\text { كما تتصف بالتقديرية أيضاً (1). }
$$

لقد شغلت تسمية (الارمن) بال الكتابات والابحاث التاريخية، فوضعت حولها عدة فرضيات، ونسجت حول ذلك العديد من القصص والروايات، ويمكن القول إن إختلاف تلك التسميات يعود بالدرجة الاساس الى أن البحث في اصول الاسماء معقد، ويصعب توثيق كل معلومة ومناقشة إحتة مدى صحتها وترجيح رأي واستبعاد رأي أخر، لما يتطلبه ذلك من دراسة أكاديمية طويلة معمقة تحتاج الى جهد كبي، من هذا المنطلق

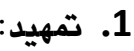

إثتهرت كوردستان على مر تاريخها الطويل بخليطها السكاني المعقد، بحيث تكونت من عناصر دينية وقومية متباينة، فكانت لتلك العناصر والتركيبات السكانية ودورها الفعال في مختلف الاوجه الحضارية والسياسية، وييدو أن من أهم تلك المدن الكوردستانية التي إحتضنت مثل تلك التركيبة المختلطة هي زاخو، إذ إستوطن فيها الى جانب الكورد عناصر دينية وقومية متعددة ك(اليهود،المسيحيين بمذاهبها المختلفة ...الخ)، ويبقى الارمن من أهم العناصر الفعالة في المدينة المذكورة، على الرغم من وجود بعض الفراغ الذي ينتاب تأريخهم في تلك المدينة،لذا إرتأى صاحب البحث الخوض في مثل هذا الموضوع، من أجل ايضاح بعض الغموض وسد أو ملء تلك الفراغات لتاريخ أبرز التركيبات السكانية في زاخو ألا وهم الارمن، وفي الوقت نفسه فتح الابواب للدراسات المستقبلية للتطرق لمثل تلك المواضيع المهملة تاريخياً، والكشف عن جوانب مهمة من تاريخ كوردستان وزاخو في أنِ واحد، على هذا الاساس فقد قسم البحث على مبحثين، المبحث الاول يتناول تسمية الارمن وأهم الاراء التي قيلت عن أصلهم، والمبحث الثاني 
بداية في الاراضي المحصورة بين نهر(هاليس)(9)، ونهري دجلة والفرات، في المنطقة التي كانت تؤلف المقاطعات الشرقية من الدولة الحثية،والتي كانت تعرف ب(هاياسا)،حيث إمتزج السكان الجدد مع سكان وشعوب

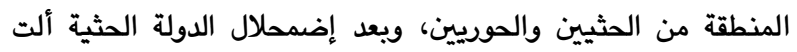

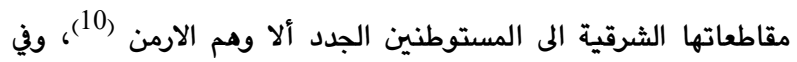
الوقت ذاته يذهب (هيودوتس) الى أن الارمن نزحوا عن أسيا ثم

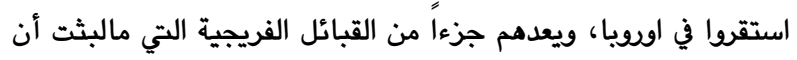
غادرت اورويا واتجهت الى أسيا مرة أخرى عبر البسفور والدردنيل،

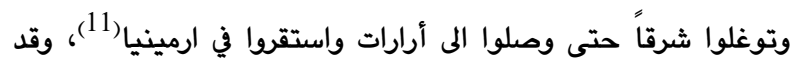
أيده في ذلك أحد الجغرافيين اليونان البارين(12). على الرغم من ذلك فان بعض الدراسات الخاصة بارمينيا ترى أن أصل الارمن من البلقان، وأن تشكلهم كأمة قد بدأ عقب مغادرتهم تدريجياً

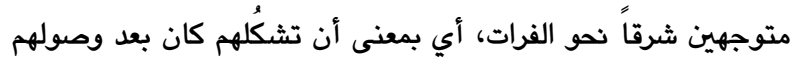
الاراضي المحصورة بين نهر هاليس من جهة، ونهري دجلة والفرات من جهة أخرى، والتي عدت فيما سبق المناطق الشرقية للدولة الحثية، وفي هذه المناطق التي تم الاثارة اليها إختلط الارمن مع الحثيين، ويعد مرود التاريخ تمكنوا من السيطرة على القبائل الساكنة في تلك المناطق، ومما سهل سيطرتهم على تلك المناطق هو التقارب الملحوظ بين لغة الارمن (الهندو-اوربية) وبين اللغة التي كان يتحدث بها سكان هذه هذان

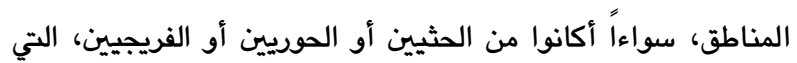
بدورها تنتمي لعائلة اللغات الهندو-اوربية(13). وفي الصدد نفسه يقول أحد الباحثين: ((...إن الارمن ينتسبون الى الجنس الاري، وكانوا قبل(1300)سنة قبل الميلاد يعيشون في جوار (أرمن) من تركيا الحالية، كما كانوا منتشرين حوالي (قونية = فريجي) ويجوار قيصري (قابيادوي/كبدوكيا)، ويعد إستيلاء السيمريين (الكيمريين) على أسيا الصغرى تقدموا نحو الشرق، فبقي قسم منهم بجوار نهر (قيزيل ايرماق)،أما القسم المهاجر فقد إستمر تقدمهم

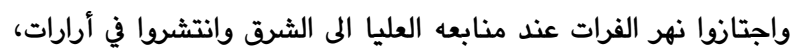

$$
\text { وعرفوا أنئذ باسم (أرما = أرمه لي)(14). }
$$

رغم ذلك فان دراسات اخرى لم تحدد أصل الارمن بشكل دقيق ولم

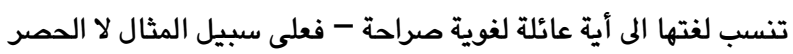

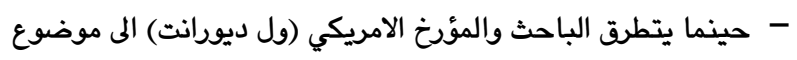
الارمن في أحد مؤلفاته القيمة، يشير الى أن الارمن يمتون بصلة قربى للحثيين والفريجيين، ولكنهم ظلوا محتفظين بأنفهم الاناضولي، وهم يتكلمون لغة أرية لم يتفق العلماء على موضعها من اللغات الارية (15).

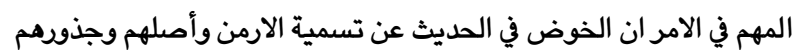
والعائلة اللغوي التي ينتمون اليها ينتابه الكثير من الغموض والتعقيد،

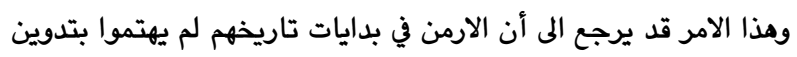
تاريخهم بالشكل المطلوب،على العكس من الشعوب والامم الاخرى التي لم تهمل هذا الجانب، بل يمكن القول ان الارمن اعتمدوا على كتابات
فان الكتابات التي تطرقت الم الارمن حاولت اللجوء الم الحكايات الخرافية لمحاولة تفسير أصل الاسم، وإن كانت تلك الروايات والحكايات إفتقرت الى الدليل العلمي. فتذهب بعض الروايات المى أن تسمية الارمن مشتقة من إسم (أرمه ناغ) أو (أرام) أحد أحفاد يافث بن نوح كما جاء في التوراة، أما (هايستان) وهي إسم أرمينيا بلغتهم، فهي مشتقة من إسم (هايغ بن توغامور) من

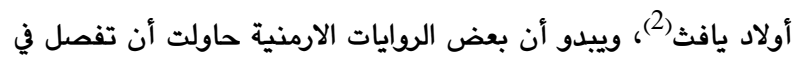
هذا الخصوص، دون الاستناد الى دلائل ثابتة، ففي إحدى المؤلفات الارمنية نجد أنها تحاول إرجاع إسم الارمن الى أحد الشخصيات يدعى (هايكوس) أو (هايغ)، الذي ينسب لاحفاد يافث بن نوح، وتقول الرواية: (....(إنه لامر حقيقي وخال من الارتياب في أن جمال وجه مايكوس وظرافة حواسه الخارجة ولطافة خطابه وإعتدال قامته ...فبهذه الالفاظ الوجيزة يعلن حسن طلعة مايكوس ومن ذلك يجب أن نعتبر في كم كان يحترم ويكرم من اولئك الامم والجبابرة، وهذا فخر وشرف عظيم لنا

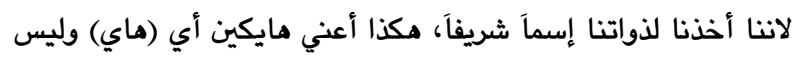
(الارمن) كما يقال في اللغة العربية.... لان الشعوب الساكنين خارج بلاد أرمينية يلقبون طائفتنا بالارمن وأقاليم بلادنا أرمينية أخذين ذلك عن

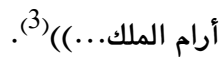
كما ورد إسم الارمن في كتابات ونقوش بيستون(4)،لكنها جاءت بهيئة البلاد أو الموطن، وذلك في إثارة أحد الملوك الاخمينيين الا وهو دارا الاول (داريوش الاول)(486-522ق.م) عند إخضاعه المناطق والاقاليم تحت سيطرته ، حيث قام الملك المذكور أنفاً بجعل تلك الاقاليم ومنها (أرمينيا) الى ولايات سماها ب(ساتراب)(5)، وهذا لايعني ان مذا الاسم ورد في هذه الفترة فقط،رغم عدم الاتيان باسم الارمن أو أرمينيا بشكل صريح،لان هناك إثارات أو تلميحات تحدثت عن الشعوب القاطنة في الاراضي التي عرفت فيما بعد باسم أرمينيا،وذلك في كتابات الحثيين ويالتحديد تلك النصوص والكتابات التي عثرت في عاصمة الحثيين (بوغازكوي)، إثر شن بعض ملوك الحثيين ضد شعوب الممالك

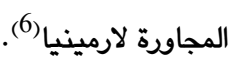
من جهة اخرى فقد ذكر إسم أرمينيا بهيئة (SOMEKHI) عند الجورجيين للدلالة على جيرانهم الجدد أي الارمن، كما استعمل تسمية كاسم لارمينيا نفسها، كما ذكر المؤرخ اليوناني (SOMKHEI) (هيكاتيوس الملتي)(7) الشعب الارمني بالشكل (أرمينوي) ${ }^{(8)}$ (ARMINOI) أما بخصوص أصل الارمن فانه على غرار تسمية الارمن، نجد أن الدراسات والمؤلفات التاريخية تختلف وتتباين اراؤها حول ذلك، ففي حين يذهب بعض المؤرخين ومنهم على سبيل المثال لا الحصر

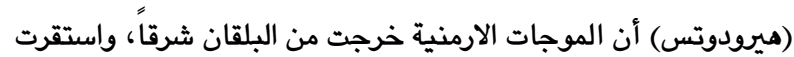


المحتمل أن زاخو كانت غير بعيدة عن مثل تلك التأثيرات الحضارية

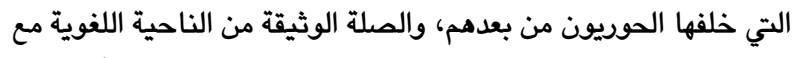
الاقوام التي عاشت في أرمينيا، والتي سنأتي على ذكرما لاحقاً. ويالرجوع الى الدراسات والبحوث الخاصة بالحوريين، تم الوصول الى نتائج مفيدة، لعل من بينها ظهور أسماء حورية لبعض المدن وحكامها الذين كانوا يحكمون في المناطق القريبة من نهر دجلة ورافده الخابور - جنوب وجنوب غربي مدينة زاخو- ومنها على سبيل المثال لا الحصر، حاكم (خابوراتم) المدعو (ننيب شويري)، وحاكم (أنوخينم) المعروف ب(شَدو شَري)،وحاكم مدينة(مَردَمَان) الذي جاء إسمه بهيئة

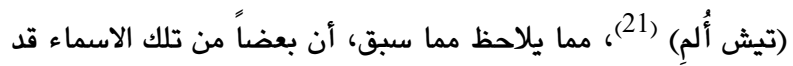
بقيت على حالها في الوقت الحاضر،أو تم تحويرما بشكل بسيط، مثال على ذلك إسم (خابوراتم) وهو الاسم المنسوب لرافد الخابور، وليس من المستبعد أن إسم (أنوخينم) هي إسم (زاخو) نفسها، ويمعنى أدق أن

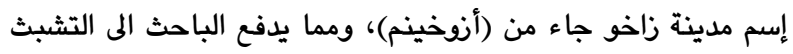
بهذا الاحتمال، الى أن المنطقة التي تم الاثارة اليها في السجلات الحورية سابقا، هي نفس المنطقة المخصصة للدراسة، وهي زاخو. لقد لاحظ عدد من الباحثين وجود شبه صلة بين اللغة الحورية ولغة مملكة اورارتو، بل إن بعض الدراسات توصلت لبعض النتائج وحددت درجة القرابة بين اللغتين، وفي ضوء تلك النتائج ويالاعتماد على وضوح التطورات اللغوية ضمن اللغة الحورية ولهجاتها، يمكن القول أن اللغتين الحورية والاورارتية تشكلان فرعين منفصلين من لغة أُم (اللغة الحوريةالاورارتية المبكرة)، وقد استقلتا الواحدة عن الاخرى خلال الالف الثالث ق.م (22)، من هذا المنطلق يمكن القول ان الارمن الذين شكلوا فيما بعد أهم التركيبات السكانية لاورارتو، قد نزحوا مع الحوريين الى العديد من المناطق،ولعل من ضمن تلك المناطق هي كوردستان على العموم،

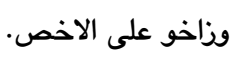
من جانب أخر يبدو أنه بعد إضمحلال الدولة الحثية،وظهور أورارتو

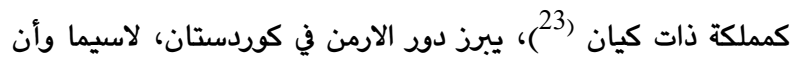

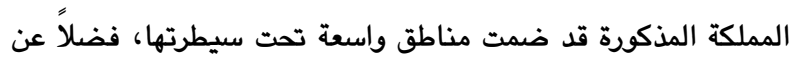

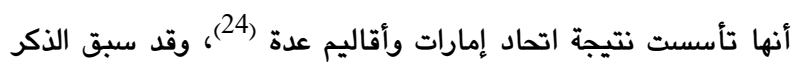
بوجود صلة بين الحوريين والاورارتيين، فظهورهم كان في منطقة واحدة، لكن بعد الزمن انفصلت القبائل الحورية عن الميتانيين، ومن ثم اتحدت بئ القبائل الحورية مع بعضها البعض وأسسوا مملكة موحدة مكونة من نائيري(25) وأورارتو (26)، ونظراً لاتساع رقعة المملكة الاورارتية، ويروذ دورما السياسي والعسكري في المنطقة، الامر الذي جعل الاثوريون

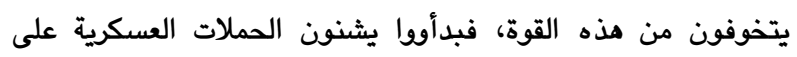
اورارتو، بحيث تكرت تلك الحملات والحروب بين الاثوريين والاورارتيين (27)، ولم تقف تلك الحملات عند هذا الحد بل أنها سببت في تغيير التركيبة السكانية للعديد من المناطق التي إستحوذ عليها الاشوريون، فالمعلوم ان إحدى السياسات التي إنتهجها الاثوريون في إسيد
ومؤلفات الامم الاخرى، حيث تضمنت بين طياتها أحوال وتاريخ الارمن، ولعل أبرز تلك الكتابات والمصادر هي الكتابات الاشورية واليونانية والفارسية ...الخ، وقد أشار مؤرخي الارمن الى هذه الحقيقة:

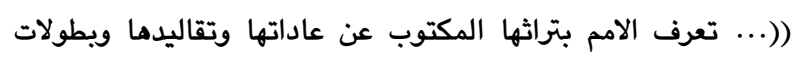
ملوكها وأممجادهم، والمتاح لكل من يرغب في البحث والدرس من خلال

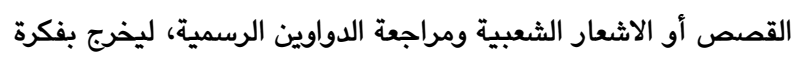
واضحة عن مذه الامة، لكن أسلافنا مع الاسف، لم يتركوا لنا أثراً

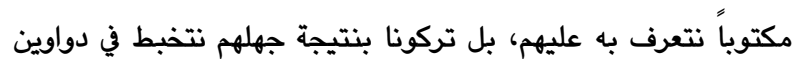

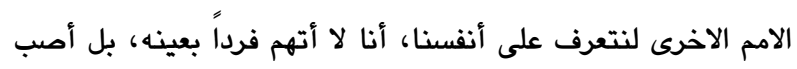
اللوم على أسلافنا كلهم لانهم لم يتطلعوا الى المستقبل ولم يهتموا بالماضي، حتى ضاع أثرهم الانساني والعلمي، باستثناء القليل القليل الذي تطوع بعضهم لتسجيله في دواوينهم وهم من الكلدان والاثوريين

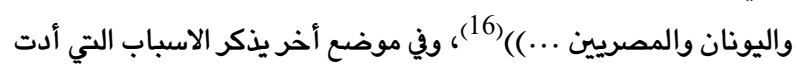
الى هذا التقصير بالقول: ((...هناك من يريد أن يعزو هذا التقصير الى الى غياب أحرف اللغة الارمنية والى استمرار الحرب، فيكون كمن لايريد

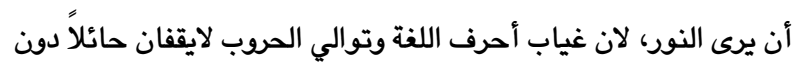
تدوين التاريخ ولو بأحرف مستعارة كما أن الامة قد حظيت بفترات

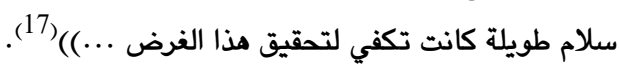

\section{3. التواجد التاريخي للارمن في كودستان وزاخو:}

ان التواجد الارمني في أجزاء كوردستان ومن ضمنها زاخو، والصلات بين الكورد والارمن لهي نقطة مهمة في تاريخ كلتا الامتين، إذ تمتد تلك

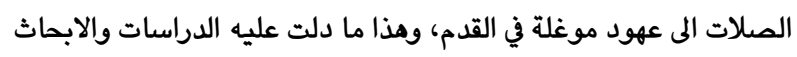
الاثارية التي أجريت في العديد من المواقع التي استوطنوا فيها جنباً الى جنب، بل استمرت تلك الصلات لتمتد لعصور تاريخية لاحقة، نتيجة

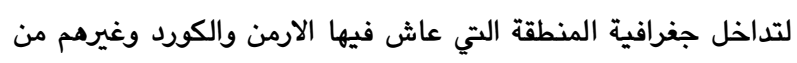
القوميات والطوائف الاخرى، مما سهل ذلك من عملية الاتصال والتوافق الحضاري،وفي الوقت نفسه لايمكن التغاضي عن نقطة اخرى تعد في

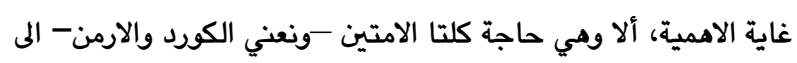
الحوار الحضاري والثقافي المتبادل، في سبيل تحقيق الوحدة الحضارية والثقافية. إن التداخل والتشابك بين تاريخ الارمن والكورد ظهر للعيان بعد هجرة الاقوام الهندو- اوربية (18)،واستيطانها في أماكن متفرقة وتوزعها زمنياً ومكانياً بشكل متفاوت،، ولعل من أبرز ذلك التداخل التاريخي بين

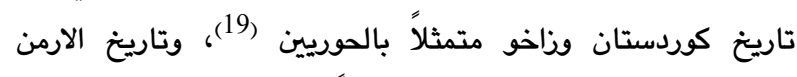
والمتمثل بالقوى التي كانت تعيش ردحاً من الزمن في أرارات، فاغلب الدراسات المختصة أظهرت أن تاريخ الارمن في أرارات قد تم من إتحاد القبائل الحورية، التي عاشت في المرتفعات حوالي بحيرة وان، حيث

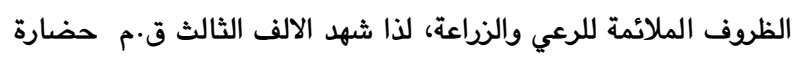
متماثلة شملت العديد من المناطق وأخذت تنتشر فيها (20)، ومن 
فضلاً عن ذلك، لم يقف دور الارمن في زاخو وكوردستان ومدى ارتباطهم بها، في عهد الملك المذكور عند الجانبين السياسي والعسكري فحسب، بل تعداه الى الجوانب الحضارية أيضاً، ويتضح ذلك بجلاء مما خلفوه ألفين من أثار ومنجزات حضارية في أرض كوردستان، وخير مثال يمكن أن

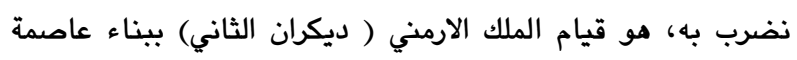
جديدة أطلق عليها إسم (ديكرانا كيرتا) أو (تيغرانوكرته (Tigranocerta) ( كوردستان،التي وقعت على الضفة اليسرى لنهر دجلة، وهي قريبة من أمد(دياريكر)، ولم يكتف بذلك فحسب بل أشاد فيها الابنية المعمارية، وحصنها بالقلاع المنيعة، وأسكن فيها الاغريق وغيرهم من الصناع والفنيين، كما بنى عدة مسارح في تلك العاصمة، لكي تعرض فيها

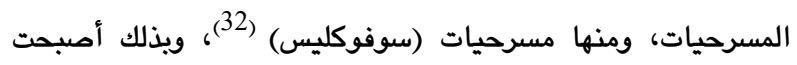
(ديكرانا كيرتا ) مركزاً مهماً إنتشرت فيها الثقافة الهيلينستية (33)، ولم وفئات تكن زاخو ببعيدة عن تلك التأثيرات الحضارية التي خلفها الملك الارمني السابق ذكره، وعن الاحداث الجارية التي كانت تجري في عاصمته

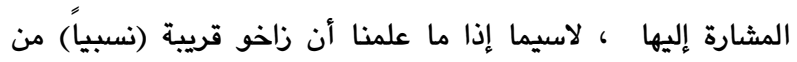
(ديكرانا كيرتا )، لذا فان أي حدث سياسي أو حضاري يجري في إني مملكة (ديكران) الارمنية، ويالاخص في عاصمته، كان ينعكس سلباً أو أو إيجاباً على زاخو . إن توسعات الملك الارمني ( ديكران الكبير )، واستيلائه ووصوله لمناطق استراتيجية، لم ترق للامبراطورية الرومانية، التي ارتابت بدورها لمثل تلك التوسعات والانتصارات التي حققها الملك الاخير، لذا تم إرسال الحملات على المملكة الارمنية، والحقت بها الهزيمة، الامر الذي ارضخ الارمن للامر الواقع، وتم فرض الصلح عليهم حسب الشروط التي أملاها الرومان عليهم، فتم تجريد تلك المملكة من الاراضي التي استولت عليها من قبل، ومنها كوردستان وسورية ولبنان وكبدوكيا(34). على الرغم من ذلك، فان دود الارمن في المنطقة بعد فترة الملك الارمني (ديكران الكبير)، وصراعها مع القوى المجاورة لم يظهر بشكلها الجلي إلا في عهد الساسانيين (651-226 م)، ففي هذه الفترة بالتحديد إثتد الصراع على الارمن وأرمينيا ووصل أوجه، وذلك بين الدولة

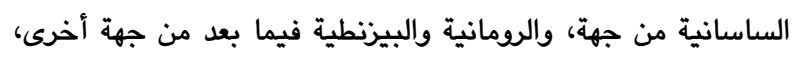
وقد إمتد هذا الصراع لسنوات طويلة، حيث شن الملوك الساسانيون والاباطرة الرومانيون والبيزنطيون العديد من الحملات من أجل الاستيلاء على أرمينيا، ووتلك المناطق التي يقطنها الارمن، وقد تخللت

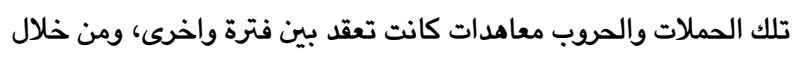
تلك المعاهدات كان كل طرف يتنازل عن أرمينيا للطرف الاخر، في حال ضعف أية قوة وتكبدما للخسائر في الحروب التي كانت تقع بينها (35)، لكن ذلك الصراع والنزاع تغير تدريجياً، وكان للارمن وأرمينيا الدود

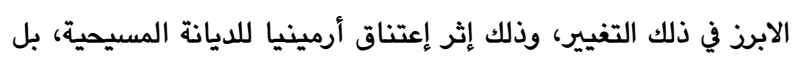

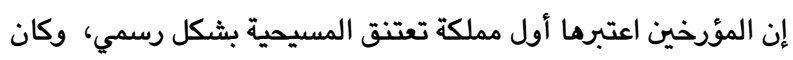

حريهم الطويلة، هو ترحيل وتهجير الاقوام من مناطقهم الاصلية،

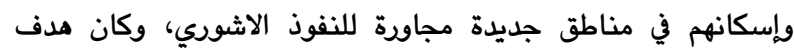
الاشوريين من ذلك كله هو إخضاع سكان المناطق والاقوام التي ثارت

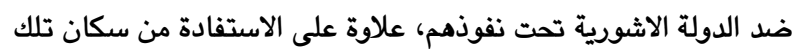

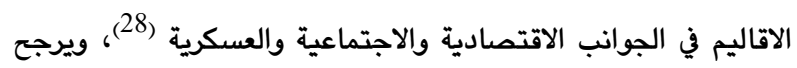
صاحب مذه الدراسة المتواضعة أن الارمن الذين شكلوا إحدى القبائل المهمة والاساسية في المملكة الاورارتية، كانوا من بين تلك القبائل التي تم تهجيرها واستيطانها في زاخو والعديد من مدن كوردستان، لاسيما وأنها (أي زاخو) قريبة من عواصم ومراكز الحكم للدولة الاشورية. ويعد إسقاط الدولة الاشورية عام (612 ق.م) من من قبل مبل التحالف الميدي والبابلي، أصبح الارمن إحدى الاقوام الرئيسة التي عاشت في كنف

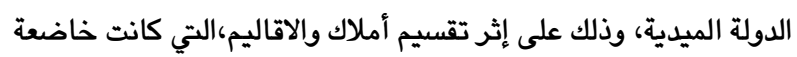
من قبل للنفوذ الاشوري، بين القوتين المتحالفتين ( ميديا ) و(بابل)، فكان الارمن من بين تلك الشعوب تحت حكم الميديين المباشر، واخذت الاخيرة تعين على أرمينيا حكاماً من أرمن، ويالمقابل يقوم الارمن بدفع تلان الضرائب للدولة الميدية (29)، يظهر جلياً ان العلاقات بين الكيانات الإنيات والمناطق الكوردية مع الكيانات والمناطق الارمنية، كانت بشكل عام تتسم بالوفاق والوئام وعدم إهمال الاخر، على العكس من علاقاتهما مع الاقوام والقوى التي هي خارج أراضي الكورد والارمن، ولنا في

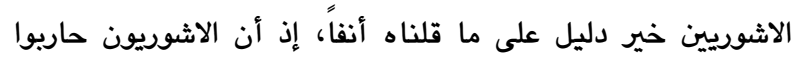
وسيطروا على أراضي كوردستان وارمينيا دون استثناء، بل نال

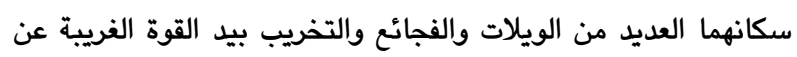
المناطق الكوردية والارمنية، ونعني بتلك القوة المشار اليها، الدولة الاثورية. ولعل أن أزهى فترات الارمن في زاخو، وكوردستان، هي بعد قيام احدى

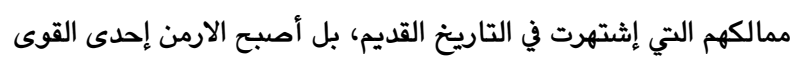

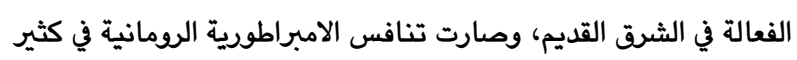
من الاحيان، وقد تمثلت بالمملكة الارمنية ويالتحديد في عهد ملكها

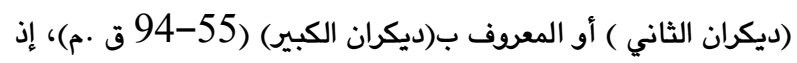

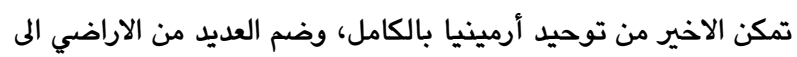

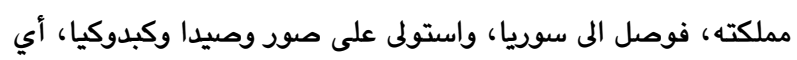
بمعنى أن سلطته إمتدت من بحر قزوين شرقاً الى البحر المتوسط غرياً، ومن القفقاس شمالاً، الى كيلكيا وفلسطين جنوياً (30)، ولم يأت هذا منا التوسع بشكل إعتباطي، بل كان نتيجة حملاته المتكرة على العديد من الجبهات، فشن حملة على منطقة ميديا، ودخل عاصمتها أكباتانا (همدان)، كما ماجم على أشور، ووصل الى أربيل، وضم شمال بلاد

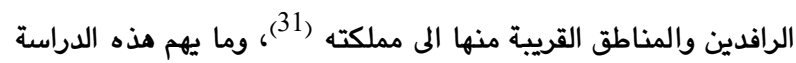
أن كوردستان بشكل عام، وزاخو بشكل خاص،كانت من بين تلك المناطق والاقاليم الخاضعة لنفوذ مملكة الارمن، وملكها (ديكران الثاني ) أو المعروف ب (ديكران الكبير). 
4- تبادل الزمالات والبعثات الدراسية بين جامعة زاخو مع الجامعات الارمنية، في سبيل التعريف بالاخر، وتشجيع عملية التفاعل والانتقال الثقافي بين الكورد والارمن.

\section{5. الهوامش والمصادر:}

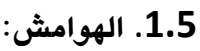

$$
\begin{aligned}
& \text { (1) فرج بصمه جي، أقوام الشرق الادنى القديم وهجراتهم، مجلة } \\
& \text { سومر، 1947،ج1،مج3،ص هـ 87-88. }
\end{aligned}
$$

(2) Father Michal Chamic Ii, History Of Armenia From B.C.2247 To The Year Of Christ 1780 Or 1229 Of The Armenian Era,Translate Johannes Avadall,Bishop"S Collge Press,Vol 1,P17-20. وينظر،محمد جمال صادق أبه زاو، موسوعة تاريخ القفقاس والجركس،منشورات دار علاء الدين،(دمشق:1996)، ص170. (3) أنطون خانجي،مختصر تاريخ الارمن، (أورشليم:1868)، ص25-26.26. (4)نق بيستون وهو النقش الذي خلفه الملك الاخميني داريوش الاول وفيها

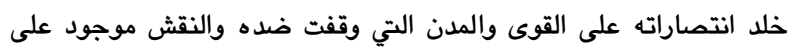
الوجه الصخري لجبل بيستون في كرمنشاه، وقد كتب هذا النقش باللغات

\section{الاخمينية والعيلامية والبابلية،للمزيد ينظر،}

R.Ghirshman, Iran From The Earlist Times To The Islamic Conques, Penguin Books, (London:1978),P153-155.

(5) H.C.Rawlinson, The Persian Cuneiform Inscription At Behistun,John W.Parker West Strand,(London:1846), Pxxvii, Historical Section Of The Foreign Office, Armenia And Kurdistan, M.H.Stationery Office, (London:1920), P11, A.T. Olmsted, Darius And Behistun Inscription, The American Journal Of Semitic Languages And Literatures, (Chicago:1938), Vol 55,No 4,P396,408.

(6) مروان المدور، الارمن عبر التاريخ،ط2، منشورات دار نويل، (دمشق:

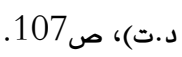

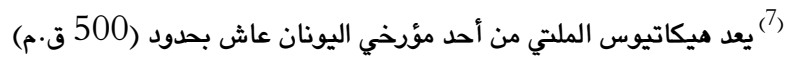
كتب مؤلفات عديدة عن الجغرافية والتاريخ والانساب واصبحت مؤلفاته

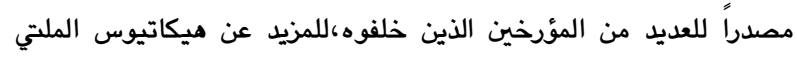

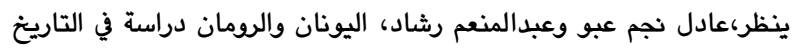

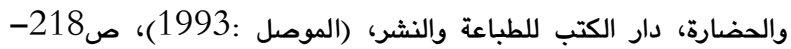

$$
\text { (8) مروان المدور، المصدر السابق، ص109. }
$$

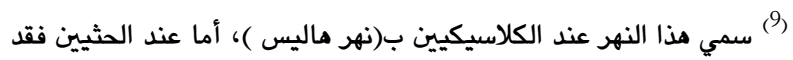
اطلق عليه ب(نهر قزل ايرق)، ويخترق هذا النهر عدة تلال ليصب في البحر

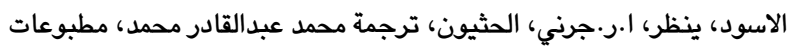

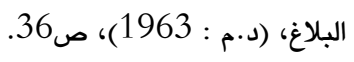

ذلك في القرن الرابع الميلادي، ويالتحديد في عام (310 م ) (36)، الامر الذي أدى الى احتدام الصراع بين الطرفين على أرمينيا، والمناطق المجاورة لها، مما أثرت بشكل أو بأخر على المناطق المتعددة، ومن لت اهن بين تلك المناطق والاراضي التي عليها الصراع الدائم على أرمينيا، هي كوردستان ومدينة زاخو، نتيجة لتجاود وقرب مدن واراضي كوردستان من المدن والاراضي الارمنية الى حدِ ما. 4. - النتائج و التوصيات:

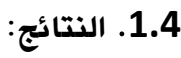
1- عدت كوردستان عموماً، وزاخو خصوصاً مكاناً أمناً للعديد من الاقوام والاديان المتباينة، وهذا الامر يعود لصفة التسامح التي اشتهر وردان بها سكان كوردستان وذاخو،فضلاً عن أن طويوغرافية المنطقة التي اشتهرت بها زاخو من وعورة وصعوية العوائق الطبيعية فيها كانت من بين الاسباب الاخرى التي دفعت تلك الاقوام للاستيطان فيها. 2- تعرض الكورد والارمن في زاخو للعديد من الاضطهادات والويلات بيد القوى الغريبة والغازية،ممايعني أن تلك القوى الغريبة عن كوردستان لم تستثن في إضطهاداتها أية تركيبة دينية أو عرقية في اية مدينة من المدن الكوردية، وهذا الامر ينطبق على مدينة زاخو أيضاً. 3- على الرغم من الاختلافات الدينية بين الكورد والارمن في كوردستان من مدئ بشكل عام،وزاخويشكل خاص، إلا أن تلك الاختلافات لم تؤد توتر بـر العلاقات بين سكان زاخو،بل على العكس من ذلك فان هذه التركيبات

الاجتماعية ساندت بعضها البعض في مواجهة الازمات والحروب.

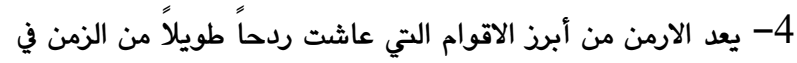
كوردستان، وفي زاخو ايضاً، ومذا الاستقرار لم يكن في فترة محددة، بل بل بل ان استقرارهم فيها كان على شكل فترات متعددة، مما يعني عراقة أصالتهم في زاخو وياقي المناطق الكوردية التي يتواجد فيها الارمن .

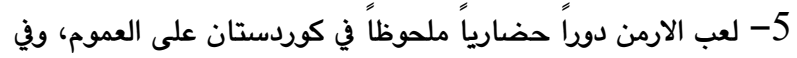
زاخو على الخصوص، لاسيما في الجوانب الثقافية والمتعلقة بنشر

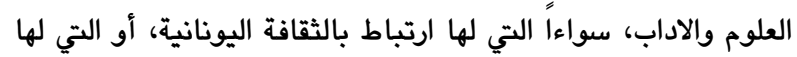

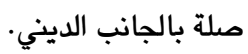
2.4

1- نظراً لان زاخو تعد من أبرز المدن الكوردية التي ضمت في تركيبتها والارمن،لذا يمكن من خلال ذلك تمتين العلاقات الكوردية -الارمنية،في سبيل الوصول الى الغاية الاسمى للكورد ومو انثاء كيان ودولة كوردية،على غرار الارمن.

2- انشاء مركز ثقافي في جامعة زاخو تقع على عاتقها حفظ وتبادل الوثائق والمصادر المعنية بالكورد والارمن على حلٍ سواء. 3- فتح اقسام خاصة في جامعة زاخو تعني بالدراسات الارمنية،بحيث تدرس فيها اللغة والتاريخ والادب الارمني. 
M.R.O .Barnett, The Archaology of Urartu ,Leiden,p10. (26) عماد شاكر أحمد، المصدر السابق، ص18)

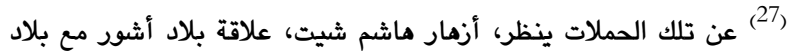
الاناضول خلال الالفين الثاني والالف ق ·م، رسالة ماجستير، (الموصل :

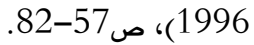
(28) حول سياسة الترحيل عند الاشوريين ينظر، إبتهال عادل ابراميم، اليهود

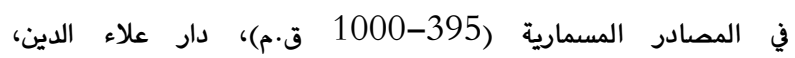
(دمشق:2014) ص214-223. (29) مروان المدور، المصدر السابق، ص119 “ فارس عثمان، المصدر السابق، ص 14. (30) فارس عثمان، المصدر نفسه، ص16 ص16.

(31) محمد الزين، تيغران، الموسوعة العربية، (دمشق : د.ت)، مئه 7)،

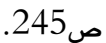
(32) سوفوكليس هو أحد كتاب المسرح اليونانيين ولد عام (495 ق.م) في

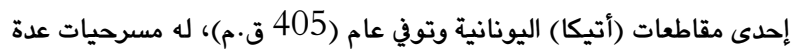
ذا طابع تهكمي، للمزيد عن سوفوكليس ينظر، أ.بتري، مدخل الى تاريخ

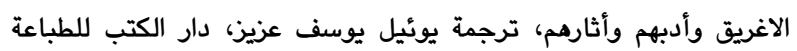

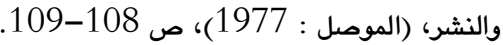

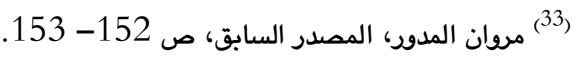

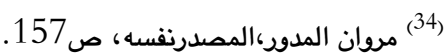

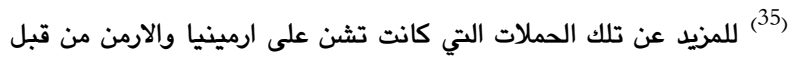
الساسانيين والبيزنطيين ينظر،

Roger C. Blockleyt, The Division Of Armenia Between The Romans And The Persians At The End Of The Fourth Century A.D, Zeitschrift Für Alte Geschichte, Bd. 36, H. 2 (2nd Qtr., 1987), Pp. 222-234,

Norman .H . Baynes, Rome And Armenia In The Fourth Century, The English Historical Review , (Chicago : 1910), VOL 25, NO 100,P625-643.

وينظر، أرثر كريستنسن، ايران في عهد الساسانيين، ترجمة يحيى الخشاب،

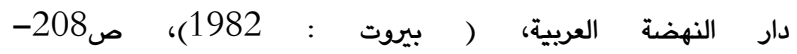
209،ص217،ص223-229،ص239-241، أرواد عدنان العلان، بهوت فارس وبيزنطة، دار ومؤسسة رسلان للطباعة والنشر والتوزيع، ( دمشق :

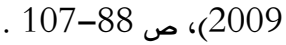

(36) عن إنتشار المسيحية في أرمينيا وعند الارمن ينظر، أرثر كريستنسن،

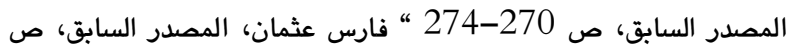

2.5

1.2.5 المصادر العربيه:

أ.بتري، مدخل الى تاريخ الاغريق وأدبهم وأثارهم، ترجمة يوئيل يوسف عزيز، دار العريه

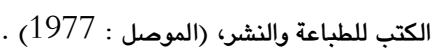

(10) ك. .س.خداورديان واخرن، تاريخ أرمنستان، ترجمة أ.كرمانيك،

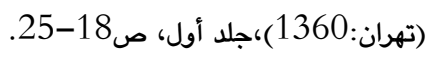

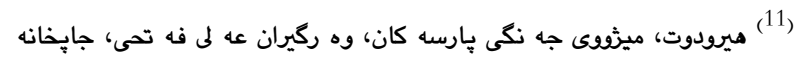

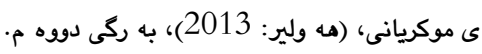

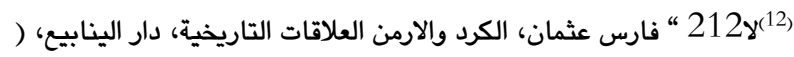
دمشق :2008)، ص13، رقيه بهزادى، قوم هاى كهن در قفقاز ماوراء قفقاز

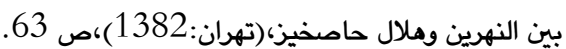
(12) Strabo, The Geography Of Strabo, William Heinemann, (London:1916) Vol 1, P 167 (13) مروان المدور، المصدر السابق، ص 107.

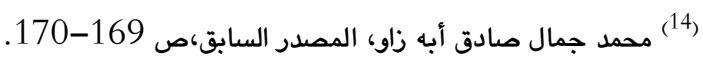

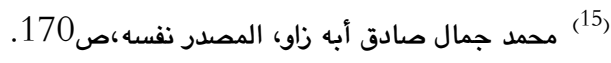

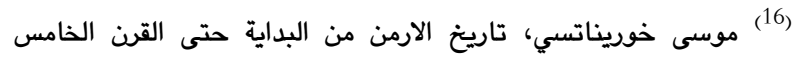

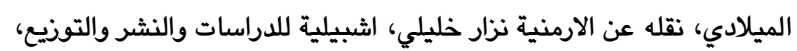

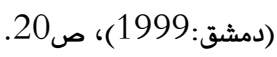
(17) موسى خوريناتسي، المصدر نفسه، ص20) (18) إختلفت الاراء حول الموطن الاصلي لقبائل (الهندو - اوربية)، فمن الاراء من ذهبت الى انها انحدرت في اواسط اسيا، في حين حددت ابحاث اخرى باستيطان تلك القبائل حول بحر قزوين، وانتشارها نحو بحيرة اورمية (ورمى)، للمزيد عن القبائل الهندو- اوربية ينظر، J.P.Mallory, In Search Of The Indo- Europeans ,Language Archaeology And Myth , (London:1990).

(19) من احدى الاقوام التي عاشت ردحاً من الزمن في كوردستان، وكانت لها

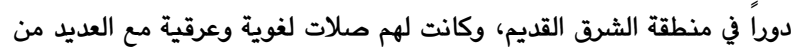

الاقوام الاخرى، للمزيد عن الحوريين ينظر، I . J .Gelb , Hurrians and Subarians, (Chicago : 1944) .

(20) سامي سعيد الاحمد و رضا جواد الهاشمي، تاريخ الشرق الادنى القديم، ايران والاناضول، (بغداد: د.ت)، ص336.

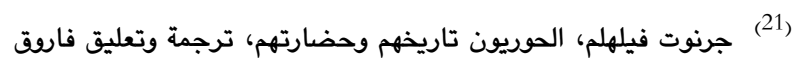

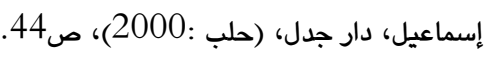

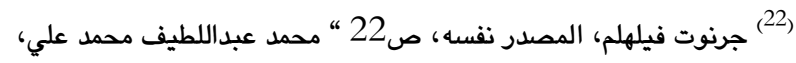
الحوريون وصلات مصر بهم في عصر الاسرة الثامنة عشرة ( من حوالي

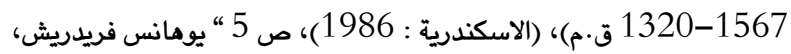

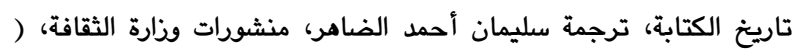
دمشق : 2004)، ص

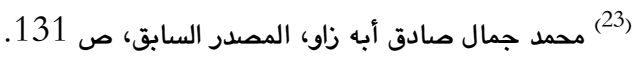

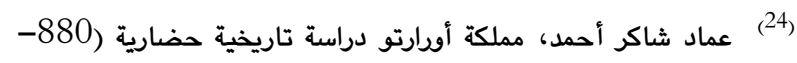

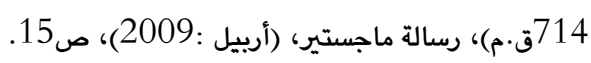

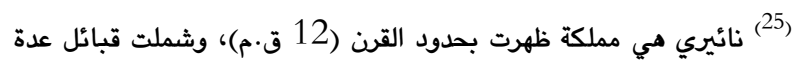
توحدت فيما بعد كمملكة موحدة، واستوطنت بالقرب من بحيرة (وان)، للمزيد ينظر، 
Historical Section Of The Foreign Office, Armenia And Kurdistan, M.H.Stationery Office, (London:1920).

J.P.Mallory, In Search Of The Indo- Europeans ,Language Archaeology And Myth , (London:1990) .

M.R.O .Barnett, The Archaology Of Urartu ,Leiden.

Norman .H . Baynes, Rome And Armenia In The Fourth Century, The English Historical Review , (Chicago : 1910), Vol 25, No 100.

R.Ghirshman,Iran From The Earlist Times To The Islamic Conques,Penguin Books,(London:1978).

Roger C. Blockleyt, The Division Of Armenia Between The Romans And The Persians At The End Of The Fourth Century A.D, Zeitschrift Für Alte Geschichte, Bd. 36, H. 2 (2nd Qtr., 1987).

Strabo, The Geography Of Strabo, William Heinemann , (London:1916) Vol 1.

$$
\text { 3.2.5 }
$$

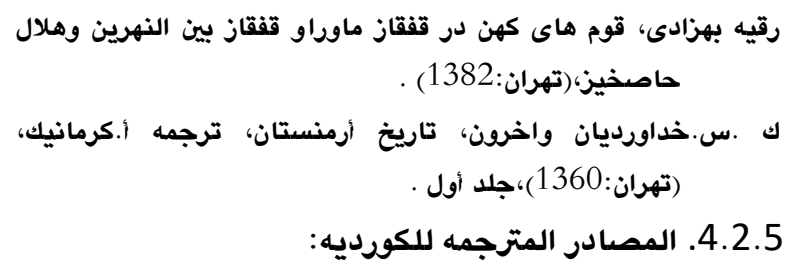

إبتهال عادل ابراهيم، اليهود في المصادر المسمارية (1000-395 ق.م)، دار علاء

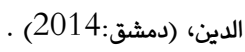

ا.ر.جرني، الحثيون، ترجمة محمد عبدالقادر محمد، مطبوعات البلاغ، (د.م : . (1963

أرثر كريستنس، ايران في عهد الساسانيين، ترجمة يحيى الخشاب، دار النهضة

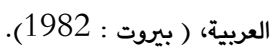

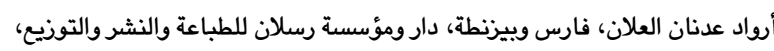

$$
\text { ( دمشق : 2009). }
$$

أنطون خانجي،مختصر تاريخ الارمن، (أورشليم:1868)

جرنوت فيلهلم، الحوريون تاريخهم وحضارتهم، ترجمة وتعليق فاروق إسماعيل،

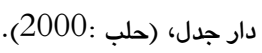

سامي سعيد الاحمد و رضا جواد الهاشمي، تاريخ الشرق الادنى القديم، ايران

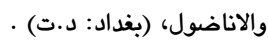

عادل نجم عبو وعبدالمنعم رشاد، اليونان والرومان دراسة في التاريخ والحضارة، دار الكتب للطباعة والنشر، (الموصل :1993) .

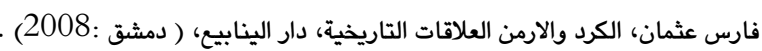
محمد عبداللطيف محمد علي، الحوريون وصلات مصر بهم في عصر الاسرة الثامنة

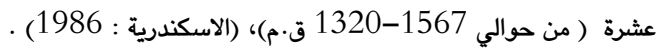

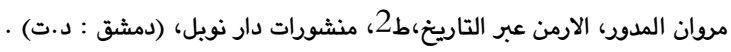

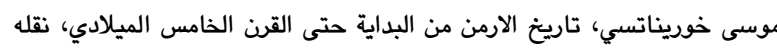

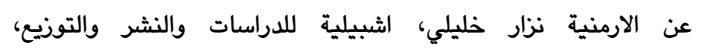
(دمشق:1999) (لارمنية نزار

يوهانس فريدريش، تاريخ الكتابة، ترجمة سليمان أحمد الظاهر، منشورات وذارة الثقافة، ( دمشق : 2004) - (200). 2.2.5

A.T. Olmsted,Darius And Behistun Inscription, The American Journal Of Semitic Languages And Literatures, (Chicago:1938), Vol 55,No 4.

Father Michal Chamic Ii, History Of Armenia From B.C.2247 To The Year Of Christ 1780 Or 1229 Of The Armenian Era,Translate Johannes Avadall,Bishop"S Collge Press, Vol 1.

J .Gelb, Hurrians And Subarians, (Chicago : 1944) . H.C.Rawlinson, The Persian Cuneiform Inscription At Behistun,John W.Parker West Strand,(London:1846), Pxxvii. 


\title{
رهـ و ريشاليّن ديروكى ييّن ئهرمهنان ل زاخو
}

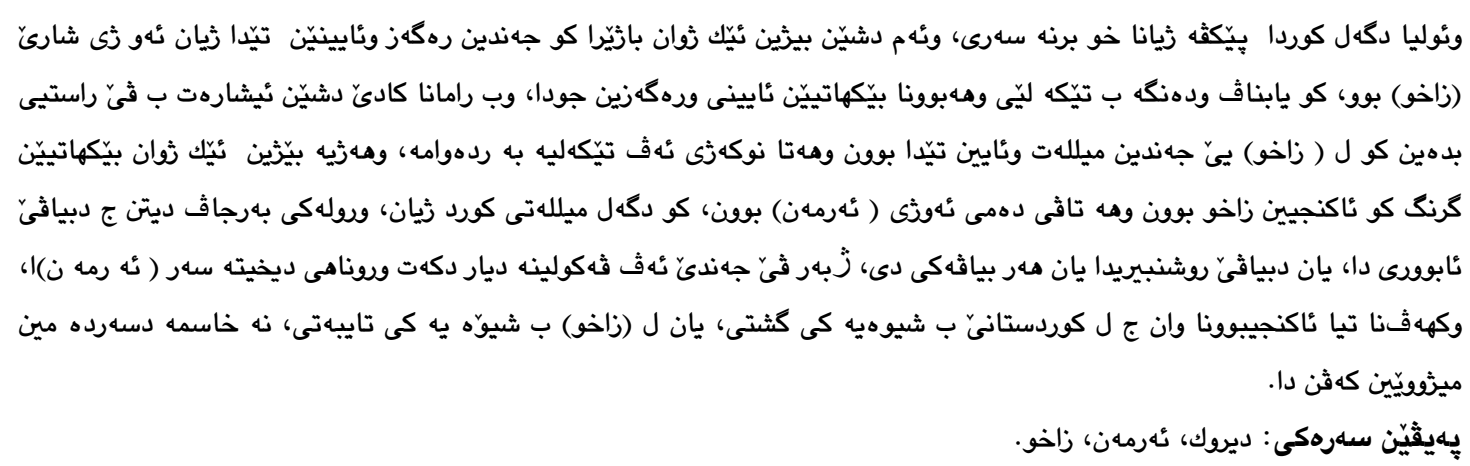

\section{Declare the Ancient Inhabit Historical (Armenians) in Zakho}

\begin{abstract}
Kurdish cities considered as accommodation of many people nations and different religion groups that nations in Kurdish arms ,Zakho is one of the cities that contain many religion and nations), consists of the famous mixed religion, and origin like (Armenians) and population inhabited in Zakho with Kurdish people that has a great role of economical and culture,This research is attempt to declare the ancient inhabit (Armenians), Kurdistan in generally, and Zakho particularly in ancient historical century .
\end{abstract}

Keywords: Ancient, Armen, Zakho. 